\title{
Hypovascular Hepatic Nodules Showing Hypointense on the Hepatobiliary-Phase Image of Gd-EOB-DTPA-Enhanced MRI to Develop a Hypervascular Hepatocellular Carcinoma: A Nationwide Retrospective Study on Their Natural Course and Risk Factors
}

\author{
Tatsuo Inoue $^{\mathrm{a}}$ Tomoko Hyodo $^{\mathrm{b}}$ Takamichi Murakami $^{\mathrm{b}}$ Yukihisa Takayamac $^{\mathrm{c}}$ \\ Akihiro Nishie $^{c}$ Atsushi Higaki $^{d}$ Keiko Korenagad, e Azusa Sakamoto ${ }^{f}$ Yukio Osaki $^{f}$ \\ Hiroshi Aikatag Kazuaki Chayama ${ }^{9}$ Takeshi Sudah ${ }^{\text {Toru Takano }}{ }^{i}$ Kennichi Miyoshi ${ }^{j}$ \\ Masahiko Kodaj Kazushi Numatak Hironori Tanakal,m Hiroko lijimal Hironori Ochin ${ }^{\mathrm{n}}$ \\ Masashi Hirooka $^{\text {n }}$ Yasuharu Imai $^{\circ}$ Masatoshi Kudo $^{a}$ \\ Departments of a Gastroenterology and Hepatology and biagnostic Radiology, Kinki University, Osakasayama, \\ 'Department of Clinical Radiology, Graduate School of Medical Sciences, Kyushu University, Fukuoka City, ${ }^{d}$ Department of \\ Hepatology and Pancreatology, Kawasaki Medical School, Kurashiki, e Department of Gastroenterology and Hepatology, \\ Kohnodai Hospital, National Center for Global Health and Medicine, Ichikawa, ${ }^{\mathrm{D}}$ Department of Gastroenterology and \\ Hepatology, Osaka Red Cross Hospital, Osaka, ${ }^{9}$ Department of Gastroenterology and Metabolism, Hiroshima University \\ Hospital, Hiroshima, Divisions of ${ }^{\mathrm{h}}$ Gastroenterology and Hepatology and 'Radiation Oncology, Graduate School of Medical and \\ Dental Sciences, Niigata University, Niigata, ${ }^{\text {j}}$ Division of Medicine and Clinical Science, Department of Multidisciplinary Internal \\ Medicine, Tottori University, Yonago, ${ }^{\mathrm{G}}$ Gastroenterological Center, Yokohama City University Medical Center, Yokohama, \\ 'Ultrasound Imaging Center and ${ }^{\mathrm{m}}$ Division of Hepatobiliary and Pancreatic Disease, Department of Internal Medicine, Hyogo \\ College of Medicine, Nishinomiya, ${ }^{n}$ Department of Gastroenterology and Metabology, Ehime University Graduate School of \\ Medicine, Toon, and ${ }^{\circ}$ Department of Gastroenterology, Ikeda Municipal Hospital, Ikeda, Japan
}

\section{Key Words}

Gadolinium ethoxybenzyl diethylenetriamine pentaacetic acid · Enhanced MRI · Hepatocellular carcinoma .

Hypervascular transformation

\section{Abstract \\ Objective: We aimed to investigate the natural outcome of nonhypervascular lesions detected in the hepatobiliary phase of gadolinium ethoxybenzyl diethylenetriamine pen-}

taacetic acid (Gd-EOB-DTPA)-enhanced MRI by performing a longitudinal study retrospectively enrolled in a nationwide manner. Methods: Between February 2008 and March 2011, 224 patients with 504 nodules that were diagnosed as nonhypervascular by imaging were recruited from institutions that participated in the present study. We examined the natural outcome of nonhypervascular lesions and evaluated the risk factors. Results: Of the 504 nodules, 173 (34.3\%) showed hypervascular transformation. The overall cumulative incidence of hypervascular transformation was $14.9 \%$ at 12

\section{KARGER}

E-Mail karger@karger.com www.karger.com/ddi
(C) 2013 S. Karger AG, Basel

0257-2753/13/0316-0472\$38.00/0
Masatoshi Kudo, MD, PhD

Division of Gastroenterology and Hepatology

Department of Internal Medicine, Kinki University Faculty of Medicine

377-2 Ohno-Higashi, Osakasayama, Osaka 589-8511 (Japan)

E-Mail m-kudo@med.kindai.ac.jp 
months and $45.8 \%$ at 24 months. Multivariate analysis using the Cox regression model revealed previous treatment history for hepatocellular carcinoma (HCC; relative risk $=1.498$; $\mathrm{p}=0.036,95 \% \mathrm{Cl} 1.03-2.19)$ and hyperintensity on $\mathrm{T} 2$ weighted images (relative risk $=1.724 ; \mathrm{p}=0.015,95 \% \mathrm{Cl}$ 1.11-2.67) were identified as independent factors for hypervascular transformation. Conclusions: Patients who have a previous treatment history for HCC and with hypointense nodules showing hyperintensity on T2-weighted images need careful follow-up because of the high incidence of hypervascular transformation.

(c) 2013 S. Karger AG, Basel

\section{Introduction}

Hepatocellular carcinoma (HCC) is one of the most common cancers worldwide and is a major cause of death in patients with cirrhosis; therefore, it is important to detect and treat HCC at an early stage. The development of screening programs for high-risk HCC patients, involving periodic ultrasonography (US) and computed tomography (CT), has enabled small HCCs less than $2 \mathrm{~cm}$ in diameter to be easily detected and safely resected. As a result, we have encountered more early-stage HCCs [1], low-grade dysplastic nodules and high-grade dysplastic nodules. Histological features of these nodules are sequential and they often display heterogeneous internal histological features, the precise differential diagnosis between borderline lesions and early-stage, highly well-differentiated HCC (early HCC) is often difficult even by histological examination $[2,3]$. Consequently, the imaging findings of these two are similar and overlapping, typically showing nonhypervascularity on dynamic CT, dynamic MRI and contrast-enhanced US; and internal portal blood supply on CT during arterial portography (CTAP) [4]. A previous study reported the existence of a significant correlation between the intranodular blood supply, as evaluated by CTAP and CT during hepatic arteriography (CTHA), and the prognosis of hepatocellular nodules associated with liver cirrhosis [5]. CTAP and CTHA are recognized as the most sensitive modalities for detecting HCC and borderline lesions [6-12]; however, a less invasive and more accurate diagnostic procedure is preferable. A hepatocyte-specific contrast agent, gadolinium ethoxybenzyl diethylenetriamine pentaacetic acid $\left(\right.$ Gd-EOB-DTPA; Primovist $\left.{ }^{\circledR}\right)$, was approved in Japan in January 2008. This contrast agent is hepatocyte specific and enhances the blood pool - it is taken up by hepatocytes and excreted into the biliary tract. The liver paren-
Table 1. Baseline characteristics of the patients

\begin{tabular}{lc}
\hline Sex (male/female) & $134 / 90$ \\
Median age, years (range) & $70(49-88)$ \\
Child-Pugh classification (A/B/C) & $187 / 37 / 0$ \\
Etiology and histology of underlying liver disease & \\
$\quad$ HCV-related chronic hepatitis & 26 \\
HCV-related cirrhosis & 118 \\
HBV-related chronic hepatitis & 14 \\
HBV-related cirrhosis & 40 \\
Others & 26 \\
Past history of HCC (yes/no) & $180 / 44$ \\
Coexistence of hypervascular HCCs (yes/no) & $85 / 139$
\end{tabular}

chyma is strongly stained white in the hepatocyte phase on T1-weighted images, 20 min after the intravenous injection of Gd-EOB-DTPA. This liver-specific MRI phase has been reported to increase the detection of focal liver lesions, including HCC [13-17], and is expected to detect early pathological change in hepatocarcinogenesis [1820]. Hypointense lesions in the hepatobiliary phase of Gd-EOB-DTPA-enhanced MRI that show nonhypervascularity on dynamic imaging are commonly encountered, and it is recommended that these lesions be monitored closely due to their potential for malignancy and transitioning to HCC through a multistep progression of hepatocarcinogenesis [21-23]. Several studies have reported the outcome of patients with these hypointense lesions [22-29]; however, only a small number of such cases have been reported and all were from a single center. The present investigation was a longitudinal retrospective nationwide study that examined the natural outcome of nonhypervascular lesions in the hepatobiliary phase of GdEOB-DTPA-enhanced MRI.

\section{Materials and Methods}

Our retrospective analysis of data was approved by the institutional review board of Kinki University Faculty of Medicine. The requirement to obtain informed consent was waived.

Patients

Between February 2008 and March 2011, 224 patients with 504 nodules that were diagnosed as nonhypervascular by imaging modalities including Gd-EOB-DTPA-enhanced MRI were recruited from institutions that participated in the present study. Baseline characteristics of the patients are shown in table 1 .

Image Analysis: Evaluation of Tumor Vascularity

Evaluation of tumor vascularity was performed using at least 2 imaging modalities including Gd-EOB-DTPA-enhanced MRI at each institution according to the local standard of care. All im- 
Table 2. Characteristics of vascularized and nonvascularized nodules

\begin{tabular}{lccc}
\hline Variables & \multicolumn{2}{l}{ Hypervascularization } & \multirow{2}{*}{ p value } \\
\cline { 2 - 3 } & yes $(\mathrm{n}=173)$ & no $(\mathrm{n}=331)$ & 0.059 \\
\hline Tumor size, mm & $9.74 \pm 4.04$ & $9.11 \pm 4.04$ & 0.014 \\
Past history of HCC treatment (yes/no) & $139 / 34$ & $232 / 99$ & 0.061 \\
Precontrast MRI T1WI (hyper-iso/low) & $24 / 149$ & $27 / 304$ & 0.72 \\
Fat containing nodule on in- and opposed-phase images (yes/no) & $36 / 137$ & $64 / 267$ & 0.037 \\
Precontrast MRI T2WI (hyper/iso-low) & $25 / 148$ & $28 / 303$ & 0.0501 \\
Dynamic image arterial phase (iso/low) & $108 / 65$ & $235 / 96$ & 0.59 \\
Dynamic image portal phase (iso/low) & $124 / 49$ & $245 / 86$ & 0.00 \\
Observation period, days & 379 & 566 & \\
\hline
\end{tabular}

Continuous variables are expressed as median with range. $\mathrm{T} 1 \mathrm{WI}=\mathrm{T} 1$-weighted imaging; $\mathrm{T} 2 \mathrm{WI}=\mathrm{T} 2$-weighted imaging; hyper = hyperintensity; iso = iso intensity; low = low intensity on MRI.

${ }^{1}$ Dynamic image means any of the available modalities were used (Gd-EOB-DTPA-enhanced MRI, dynamic CT, contrast-enhanced US, CTHA and CTAP). When CTHA and CTAP were performed, we adopted those image findings.

ages were interpreted independently by an experienced boardcertified radiologist or gastroenterologist who knew that the patients were at risk for HCC but had no other clinical information. A nonhypervascular nodule was defined as a nodule in which all parts showed nonhypervascularity relative to the surrounding liver parenchyma during the arterial phase of dynamic imaging when any of the available modalities were used (Gd-EOB-DTPAenhanced MRI, dynamic CT, CTHA and contrast-enhanced US). The exclusion criteria for hypointense lesions in the hepatobiliary-phase image of Gd-EOB-DTPA-enhanced MRI were as follows: (a) hypervascularity on initial dynamic MRI (i.e. exclusion of classical HCC and other hypervascular tumors); (b) delayed enhancement on initial dynamic MRI (i.e. exclusion of slow-filling hemangiomas); (c) strong high intensity on T2-weigthed images (i.e. excluding cysts), and (d) lesion size of $<2 \mathrm{~mm}$ (since the slice thickness for the hepatobiliary phase of Gd-EOB-DTPA-enhanced MRI was $3 \mathrm{~mm}$ ).

\section{Statistical Analysis}

Continuous variables were presented as the median and range. Continuous variables such as tumor size and observation period were compared by Mann-Whitney U test, and other categorical variables were compared by Fisher's exact test or $\chi^{2}$ test. Based on the analysis of lesions, the cumulative risk of a nonhypervascular tumor turning into classical HCC was calculated according to the Kaplan-Meier method. We calculated relative risk using Cox proportional hazard regression analysis. Based on the analysis of tumors, hypervascularization curves were constructed according to the Kaplan-Meier method, and the log-rank test was used for statistical comparisons. A p value $<0.05$ was considered to denote a statistically significant difference. All analyses were performed with SPSS statistics software (version 11, SPSS, Chicago, Ill., USA) for Microsoft Windows.
Table 3. Univariate analysis

\begin{tabular}{ll}
\hline Variables & p value \\
\hline Tumor diameter $>11 \mathrm{~mm}$ & $\mathbf{0 . 0 1 8}$ \\
Previous treatment history for HCC & $\mathbf{0 . 0 2 3}$ \\
$\begin{array}{l}\text { Coexistence of hypervascular HCC } \\
\text { MRI finding }\end{array}$ & 0.32 \\
$\quad \begin{array}{l}\text { T1-weighted imaging } \\
\text { T2-weighted imaging }\end{array}$ & $\mathbf{0 . 0 0}$ \\
$\begin{array}{l}\text { Fat-containing nodule on in- and opposed-phase } \\
\text { images }\end{array}$ & $\mathbf{0 . 0 0 4}$ \\
Image findings of dynamic study ${ }^{1}$ & 0.84 \\
$\quad \begin{array}{l}\text { Arterial phase } \\
\text { Portal phase }\end{array}$ & 0.06 \\
\end{tabular}

Bold $\mathrm{p}$ values are statistically significant.

${ }^{1}$ Dynamic study means any of the available modalities were used (Gd-EOB-DTPA-enhanced MRI, dynamic CT, contrast-enhanced US, CTHA and CTAP). When CTHA and CTAP were performed, we adopted those image findings.

\section{Results}

\section{Nodule Characteristics}

Table 2 shows the characteristics of the nodules that were vascularized and those that were not. Of the 504 nodules, 173 (34.3\%) showed hypervascular transformation in the arterial phase of dynamic imaging during the follow-up period. The results of data analysis using Fish- 


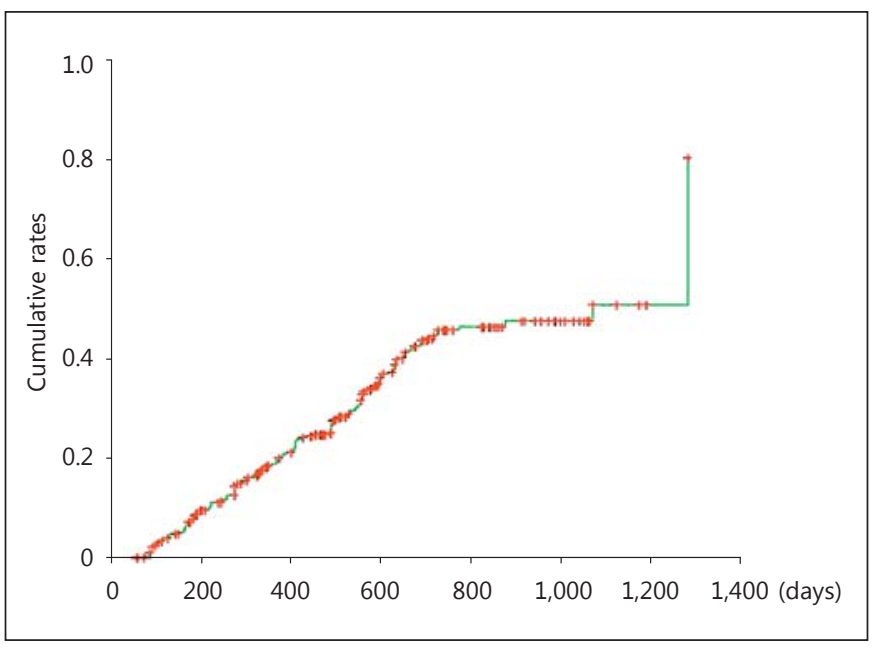

Fig. 1. Cumulative rates for hypointense lesions to hypervascularization. The cumulative rates for hypointense lesions that became classical HCC were $14.9 \%$ at 1 year and $45.8 \%$ at 2 years.

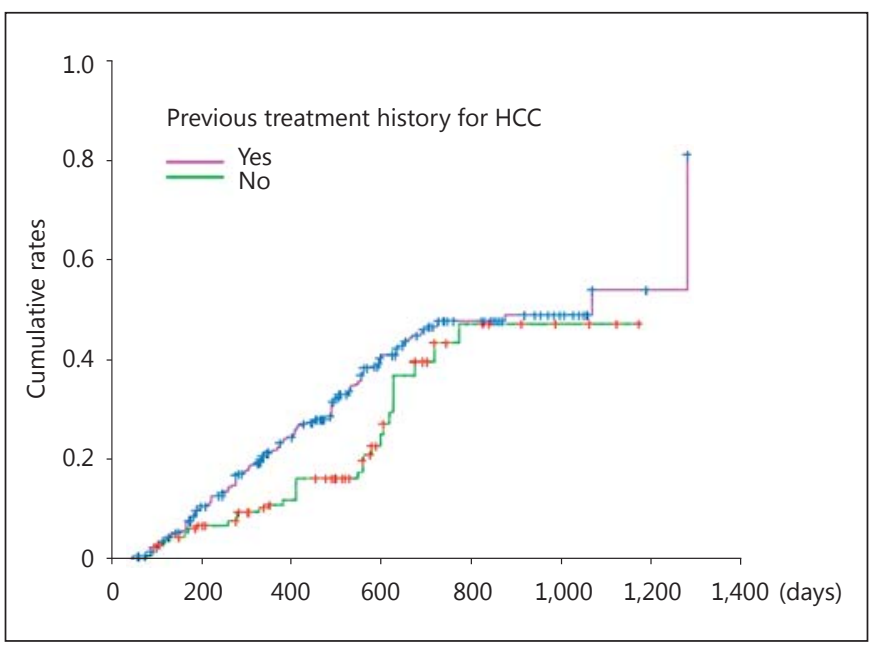

Fig. 2. Differences in the incidence of hypervascular transformation in relation to previous treatment history for HCC. The logrank test $\mathrm{p}$ value was 0.023 , indicating that the incidence of hypervascular transformation was significantly higher among patients who had a previous history of treatment for HCC.

er's exact test showed that, at the start of follow-up, nodules with and without vascularization showed significant differences in the proportion of patients who had a past history of HCC $(\mathrm{p}=0.014)$ and the incidence of tumors displaying hyperintensity on $\mathrm{T} 2$-weighted images $(\mathrm{p}=$ 0.037). There were no differences between nodules with and without vascularization with respect to average tu-
Table 4. Multivariate analysis

\begin{tabular}{llll}
\hline Variables & $\begin{array}{l}\text { Relative } \\
\text { risk }\end{array}$ & $95 \%$ CI & $\begin{array}{l}\mathrm{p} \\
\text { value }\end{array}$ \\
\hline $\begin{array}{l}\text { Previous treatment history } \\
\quad \text { for HCC (yes) }\end{array}$ & 1.498 & $1.026-2.187$ & $\mathbf{0 . 0 3 6}$ \\
$\begin{array}{l}\text { Tumor diameter }>11 \mathrm{~mm} \\
\text { T1-weighted imaging (low) }\end{array}$ & 1.344 & $0.971-1.860$ & 0.075 \\
T2-weighted imaging (hyper) & 1.724 & $0.675-1.420$ & 0.910 \\
\hline
\end{tabular}

Bold $\mathrm{p}$ values are statistically significant.

mor diameter, T1-weighted images, being fat containing on in- and opposed-phase images, and arterial and portal-phase images of dynamic study.

Cumulative Incidence of Hypervascular Transformation

The overall cumulative incidence of hypervascular transformation was $14.9 \%$ at 12 months and $45.8 \%$ at 24 months (fig. 1). Univariate analysis using the log-rank test revealed that a past history of HCC, tumor diameter $>11 \mathrm{~mm}$, and T1- and T2-weighted images were correlated with hypervascular transformation (table 3). Next, the four significant factors identified by univariate analysis were analyzed by multivariate analysis using the Cox regression model (table 4). Previous treatment history for $\mathrm{HCC}$ (relative risk $=1.498 ; \mathrm{p}=0.036,95 \%$ CI $1.03-$ 2.19 ) and hyperintensity on T2-weighted images (relative risk $=1.724 ; \mathrm{p}=0.015,95 \%$ CI $1.11-2.67)$ were identified as independent factors for hypervascular transformation. Subsequently, we compared the incidence of hypervascular transformation of tumors with these risk factors based on the Kaplan-Meier curve. The incidence of hypervascularization was significantly higher in the groups with these prognostic factors (fig. 2-4).

\section{Discussion}

Since the introduction of Gd-EOB-DTPA-enhanced MRI in clinical practice, there have been several reports describing the effectiveness of the hepatobiliary phase of Gd-EOB-DTPA-enhanced MRI for the detection of HCC, including early HCC, because these lesions tend to show hypointensity on hepatobiliary-phase images [17, 30]. Although these hypointense lesions have been reported to exhibit a high rate of hypervascular transformation [22-29], the natural histories of such nodules had not 


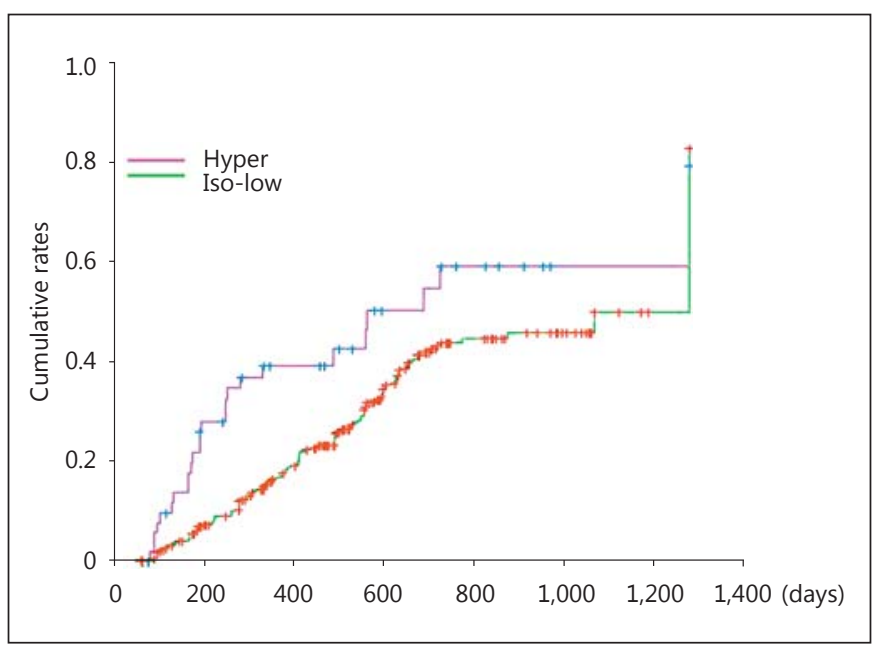

Fig. 3. Differences in the incidence of hypervascular transformation in relation to the T2-weighted images. The log-rank test $\mathrm{p}$ value was 0.004 , indicating that the incidence of hypervascular transformation was significantly higher for hyperintense tumors.

been investigated in a nationwide study involving a large number of cases. Therefore, we aimed to identify tumor imaging findings associated with subsequent hypervascular transformation in nonhypervascular tumors that show hypointensity in the hepatobiliary phase of Gd-EOBDTPA-enhanced MRI in patients with chronic liver diseases. Among the initial imaging findings analyzed in the present study, previous treatment history for HCC and hyperintensity on T2-weighted images were significantly correlated with hypervascular transformation, indicating that these parameters may be useful predictive marker factors for hypervascular transformation of nonhypervascular tumors. Even though we performed curative therapy by resection or radiofrequency ablation to prevent HCC recurrence, the recurrence rate was nonetheless extremely high [31-33]. A longer duration of infection with hepatitis $B$ or $C$ virus is usually associated with progression of liver fibrosis. In that condition, oxidative stress in the liver is considered to be higher, and genetic and epigenetic mechanisms activate oncogenes and inactivate tumor suppressor genes. Activation of these pathological processes results in hepatocarcinogenesis [34-36]. Patients who have a previous history of treatment for HCC are likely to have suffered from the condition for a long time, resulting in a high prevalence of hepatocarcinogenesis. Considering this status, it is speculated that nonhypervascular tumors of patients who have past history of HCC have been suffering such an oxidative stress for a long time, leading to hypervascular transformation as the next step at an earlier period. Another variable associated with an increased risk of hypervascular transformation was hyperintensity on T2-weighted images. Hyodo et al. [27] reported that the most important variable associated with an increased risk of hypervascular transformation was hyperintensity on T2-weighted images. They discussed that T2-weighted images might reflect peliotic changes in the intratumoral sinusoids of HCC, and that nodular regeneration, fibrosis and scarring that occur in the course of cirrhosis occasionally appear as hyperintense round lesions on T2-weighted images. For that reason, it is speculated that nonhypervascular tumors, for example dysplastic nodules with fibrosis and scarring, can be hyperintense on T2-weighted images [37, 38]. The findings from our present study suggest that the combination of T2-weighted images and hepatobiliaryphase images of Gd-EOB-DTPA-enhanced MRI could be useful in the prediction of hypervascular transformation of previously nonhypervascular nodules.

Based on patient background in the present study, the enrolled patients are considered to represent the daily practice of patients who are suffering from chronic liver diseases. Therefore, when we detected nonhypervascular tumors on hepatobiliary-phase image, it was important to recheck the findings of the T2 image of the precontrast MRI and to confirm the presence or absence of treatment history for HCC. Although we conducted a cooperative study and collected many nonhypervascular tumors and investigated the natural outcome of hypointense lesions in a nationwide manner, this study did have some limitations. The principal limitation was the variety of imaging equipment used. This limitation may have been inevitable because this was a multicenter study. Second, this was a retrospective study and, therefore, on imaging analysis our study was potentially limited by consensus review, although well-trained radiologists and physicians reviewed the images. Third, the interval between follow-up examinations was not consistent; a fixed follow-up interval would have enabled us to calculate more accurately. Fourth was the lack of a pathological diagnosis of the nodules examined. However, we consider that our imagebased findings have clinical implications even though the pathological findings were unknown. Also, the purpose of the present study was to evaluate the incidence and predictive factors for hypervascular transformation in nonhypervascular tumors detected on the hepatobiliary phase of Gd-EOB-DTPA-enhanced MRI, not to distinguish between dysplastic nodules, early HCCs and welldifferentiated HCCs that show to be nonhypervascular on dynamic study. 

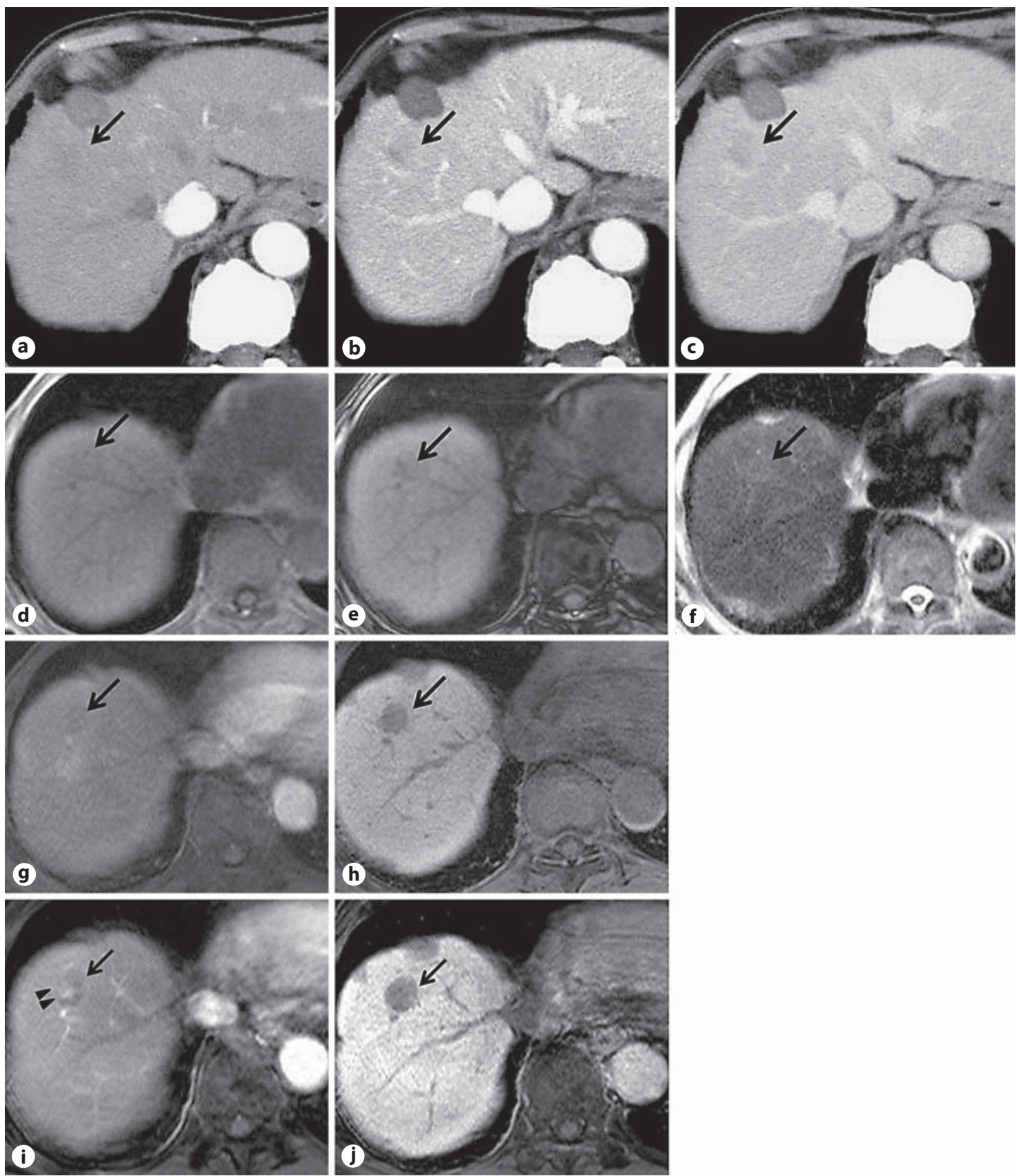

Fig. 4. A 79-year-old man with hepatitis C-related cirrhosis. ac Initial dynamic CT. The hepatic nodule in segment 8 of the liver showed no contrast enhancement (arrow). d-e Initial Gd-EOBDTPA-enhanced MRI. The nodule showed fat deposition on chemical-shift imaging (arrow, in-phase, d; out-of phase, e). On T2-weighted imaging, the nodule showed slight hyperintensity (arrow, f). Images for the arterial phase (arrow, $\mathbf{g}$ ) and hepatobiliary phase (arrow, $\mathbf{h}$ ) of Gd-EOB-DTPA-enhanced MRI at the start

of follow-up showed a hypointense nodule. $\mathbf{i}$ The arterial-phase image from Gd-EOB-DTPA-enhanced MRI 16 months after the start of follow-up showed a hypervascular spot in the nodule: tumor (arrow), hypervascular spot (arrowheads). j A hepatobiliaryphase image of Gd-EOB-DTPA-enhanced MRI 16 months after the start of follow-up showed a markedly hypointense nodule (arrow). 
In conclusion, patients who have a previous treatment history for HCC and with hypointense nodules showing hyperintensity on T2-weighted images need careful follow-up because of the high incidence of hypervascular transformation.

\section{Disclosure Statement}

The authors have no conflicts of interest to declare.

\section{References}

1 Kudo M: Early hepatocellular carcinoma: definition and diagnosis. Liver Cancer 2013;2: 69-72.

2 Lee JM, Yoon JH, Joo I, Woo HS: Rencet advances in $\mathrm{CT}$ and $\mathrm{MR}$ imaging for evaluation of hepatocellular carcinoma. Liver Cancer 2012;1:22-40.

-3 Joo I, Choi BI: New paradigm for management of hepatocellular carcinoma by imaging. Liver Cancer 2012;1:94-109.

-4 Shinmura R, Matsui O, Kadoya M, Kobayashi S, Terayama N, Sanada J, Demachi H, Gabata T: Detection of hypervascular malignant foci in borderline lesions of hepatocellular carcinoma: comparison of dynamic multi-detector row CT, dynamic MR imaging and superparamagnetic iron oxide-enhanced MR imaging. Eur Radiol 2008;18:1918-1924.

$\checkmark 5$ Hayashi M, Matsui O, Ueda K, Kawamori Y, Gabata T, Kadoya M: Progression to hypervascular hepatocellular carcinoma: correlation with intranodular blood supply evaluated with CT during intraarterial injection of contrast material. Radiology 2002;225:143149.

6 Matsui O, Kadoya M, Suzuki M, Inoue K, Itoh $\mathrm{H}$, Ida M, Takashima T: Work in progress: dynamic sequential computed tomography during arterial portography in the detection of hepatic neoplasms. Radiology 1983;146:721727.

7 Matsui O, Kadoya M, Kameyama T, Yoshikawa J, Takashima T, Nakanuma Y, Unoura M, Kobayashi K, Izumi R, Ida M, et al: Benign and malignant nodules in cirrhotic livers: distinction based on blood supply. Radiology 1991;178:493-497.

8 Ueda K, Matsui O, Kawamori Y, Nakanuma Y, Kadoya M, Yoshikawa J, Gabata T, Nonomura A, Takashima T: Hypervascular hepatocellular carcinoma: evaluation of hemodynamics with dynamic CT during hepatic arteriography. Radiology 1998;206:161-166.

-9 Hayashi M, Matsui O, Ueda K, Kawamori Y, Kadoya M, Yoshikawa J, Gabata T, Takashima T, Nonomura A, Nakanuma Y: Correlation between the blood supply and grade of malignancy of hepatocellular nodules associated with liver cirrhosis: evaluation by CT during intraarterial injection of contrast medium. AJR Am J Roentgenol 1999;172:969-976.
0 Inoue E, Fujita M, Hosomi N, Sawai Y, Hashimoto T, Kuroda C, Nakano H, Sasaki Y, Ishiguro $\mathrm{S}$ : Double phase CT arteriography of the whole liver in the evaluation of hepatic tumors. J Comput Assist Tomogr 1998;22:6468.

11 Murakami T, Takamura M, Kim T, Hori M, Federle MP, Onishi H, Tomoda K, Nakamura $\mathrm{H}$ : Double phase CT during hepatic arteriography for diagnosis of hepatocellular carcinoma. Eur J Radiol 2005;54:246-252.

12 Bruix J, Sherman M, Llovet JM, Beaugrand M, Lencioni R, Burroughs AK, Christensen E, Pagliaro L, Colombo M, Rodes J: Clinical management of hepatocellular carcinoma: conclusions of the Barcelona-2000 EASL conference - European Association for the Study of the Liver. J Hepatol 2001;35:421-430.

13 Huppertz A, Balzer T, Blakeborough A, Breuer J, Giovagnoni A, Heinz-Peer G, Laniado M, Manfredi RM, Mathieu DG, Mueller D, et al: Improved detection of focal liver lesions at MR imaging: multicenter comparison of gadoxetic acid-enhanced MR images with intraoperative findings. Radiology 2004;230: 266-275.

14 Halavaara J, Breuer J, Ayuso C, Balzer T, Bellin MF, Blomqvist L, Carter R, Grazioli L, Hammerstingl R, Huppertz A, et al: Liver tumor characterization: comparison between liverspecific gadoxetic acid disodium-enhanced MRI and biphasic CT - a multicenter trial. J Comput Assist Tomogr 2006;30:345-354.

15 Kim YK, Kim CS, Han YM, Kwak HS, Jin GY, Hwang SB, Chung GH, Lee SY, Yu HC: Detection of hepatocellular carcinoma: gadoxetic acid-enhanced 3-dimensional magnetic resonance imaging versus multi-detector row computed tomography. J Comput Assist Tomogr 2009;33:844-850.

16 Kim SH, Lee J, Kim MJ, Jeon YH, Park Y, Choi D, Lee WJ, Lim HK: Gadoxetic acid-enhanced MRI versus triple-phase MDCT for the preoperative detection of hepatocellular carcinoma. AJR Am J Roentgenol 2009;192:16751681.

17 Inoue T, Kudo M, Komuta M, Hayaishi S, Ueda T, Takita M, Kitai S, Hatanaka K, Yada N, Hagiwara S, et al: Assessment of Gd-EOBDTPA-enhanced MRI for HCC and dysplastic nodules and comparison of detection sensitivity versus MDCT. J Gastroenterol 2012; 47:1036-1047.
18 Tanimoto A, Lee JM, Murakami T, Huppertz A, Kudo M, Grazioli L: Consensus report of the 2nd International Forum for Liver MRI. Eur Radiol 2009;19(suppl 5):S975-S989.

19 Kogita S, Imai Y, Okada M, Kim T, Onishi $\mathrm{H}$, Takamura M, Fukuda K, Igura T, Sawai $\mathrm{Y}$, Morimoto O, et al: Gd-EOB-DTPA-enhanced magnetic resonance images of hepatocellular carcinoma: correlation with histological grading and portal blood flow. Eur Radiol 2010;20:2405-2413.

20 Kitao A, Zen Y, Matsui O, Gabata T, Kobayashi S, Koda W, Kozaka K, Yoneda N, Yamashita T, Kaneko S, et al: Hepatocellular carcinoma: signal intensity at gadoxetic acidenhanced MR imaging - correlation with molecular transporters and histopathologic features. Radiology 2010;256:817-826.

21 Takayama T, Makuuchi M, Hirohashi S, Sakamoto M, Okazaki N, Takayasu K, Kosuge T, Motoo Y, Yamazaki S, Hasegawa H: Malignant transformation of adenomatous hyperplasia to hepatocellular carcinoma. Lancet 1990;336:1150-1153.

22 Kumada T, Toyoda H, Tada T, Sone Y, Fujimori M, Ogawa S, Ishikawa T: Evolution of hypointense hepatocellular nodules observed only in the hepatobiliary phase of gadoxetate disodium-enhanced MRI. AJR Am J Roentgenol 2011;197:58-63.

23 Akai H, Matsuda I, Kiryu S, Tajima T, Takao $\mathrm{H}$, Watanabe $\mathrm{Y}$, Imamura $\mathrm{H}$, Kokudo N, Akahane M, Ohtomo K: Fate of hypointense lesions on Gd-EOB-DTPA-enhanced magnetic resonance imaging. Eur J Radiol 2012;81: 2973-2977.

24 Motosugi U, Ichikawa T, Sano K, Sou H, Onohara K, Muhi A, Amemiya F, Enomoto N, Matsuda M, Fujii H, et al: Outcome of hypovascular hepatic nodules revealing no gadoxetic acid uptake in patients with chronic liver disease. J Magn Reson Imaging 2011;34:88-94.

25 Takayama Y, Nishie A, Nakayama T, Asayama Y, Ishigami K, Kakihara D, Ushijima Y, Fujita N, Hirakawa M, Honda H: Hypovascular hepatic nodule showing hypointensity in the hepatobiliary phase of gadoxetic acid-enhanced MRI in patients with chronic liver disease: prediction of malignant transformation. Eur J Radiol 2012;81:3072-3078. 
26 Kobayashi S, Matsui O, Gabata T, Koda W, Minami T, Ryu Y, Kozaka K, Kitao A: Relationship between signal intensity on hepatobiliary phase of gadolinium ethoxybenzyl diethylenetriaminepentaacetic acid (Gd-EOBDTPA)-enhanced MR imaging and prognosis of borderline lesions of hepatocellular carcinoma. Eur J Radiol 2012;81:3002-3009.

27 Hyodo T, Murakami T, Imai Y, Okada M, Hori M, Kagawa Y, Kogita S, Kumano S, Kudo M, Mochizuki T: Hypovascular nodules in patients with chronic liver disease: risk factors for development of hypervascular hepatocellular carcinoma. Radiology 2013;266: 480-490.

28 Higaki A, Ito K, Tamada T, Teruki S, Yamamoto A, Higashi H, Kanki A, Sato T, Noda Y: High-risk nodules detected in the hepatobiliary phase of Gd-EOB-DTPA-enhanced MR imaging in cirrhosis or chronic hepatitis: incidence and predictive factors for hypervascular transformation, preliminary results. J Magn Reson Imaging 2013;37:1377-1383.
29 Takechi M, Tsuda T, Yoshioka S, Murata S, Tanaka H, Hirooka M, Mochizuki T: Risk of hypervascularization in small hypovascular hepatic nodules showing hypointense in the hepatobiliary phase of gadoxetic acid-enhanced MRI in patients with chronic liver disease. Jpn J Radiol 2012;30:743-751.

30 Sano K, Ichikawa T, Motosugi U, Sou H, Muhi AM, Matsuda M, Nakano M, Sakamoto M, Nakazawa T, Asakawa M, et al: Imaging study of early hepatocellular carcinoma: usefulness of gadoxetic acid-enhanced MR imaging. Radiology 2011;261:834-844.

31 Shiina S, Tateishi R, Arano T, Uchino K, Enooku K, Nakagawa H, Asaoka Y, Sato T, Masuzaki R, Kondo Y, et al: Radiofrequency ablation for hepatocellular carcinoma: $10-$ year outcome and prognostic factors. Am J Gastroenterol 2012;107:569-577, quiz 578.

32 Wood TF, Rose DM, Chung M, Allegra DP, Foshag LJ, Bilchik AJ: Radiofrequency ablation of 231 unresectable hepatic tumors: indications, limitations, and complications. Ann Surg Oncol 2000;7:593-600.

33 Cho YK, Rhim H, Noh S: Radiofrequency ablation versus surgical resection as primary treatment of hepatocellular carcinoma meeting the Milan criteria: a systematic review. J Gastroenterol Hepatol 2011;26:1354-1360.
34 Nishida N, Goel A: Genetic and epigenetic signatures in human hepatocellular carcinoma: a systematic review. Curr Genomics 2011; 12:130-137.

35 Nishida N, Kudo M, Nagasaka T, Ikai I, Goel A: Characteristic patterns of altered DNA methylation predict emergence of human hepatocellular carcinoma. Hepatology 2012;56: 994-1003.

36 Nishida N, Kudo M: Recent advancements in comprehensive genetic analyses for human hepatocellular carcinoma. Oncology 2013; 84(suppl 1):93-97.

37 Ohtomo K, Baron RL, Dodd GD 3rd, Federle MP, Ohtomo Y, Confer SR: Confluent hepatic fibrosis in advanced cirrhosis: evaluation with MR imaging. Radiology 1993;189:871874.

38 Kim T, Baron RL, Nalesnik MA: Infarcted regenerative nodules in cirrhosis: CT and MR imaging findings with pathologic correlation. AJR Am J Roentgenol 2000;175:1121-1125.
Hypovascular Hepatic Nodules: Their Natural Course and Risk Factors 